\title{
A EDUCAÇÃO AMBIENTAL NA VALORIZAÇẪO DA FAUNA NATIVA: DA ARENA À ESCOLA
}

\author{
Francisco Alves de Sousa Filho ${ }^{1}$ \\ Francisco Arlan Sales ${ }^{2}$ \\ Letícia Sousa dos Santos Ferreira ${ }^{3}$ \\ Patrícia Maria Martins Nápolis ${ }^{4}$
}

\begin{abstract}
Resumo: O tema futebol pode ser trabalhado em várias disciplinas curriculares, assim como pode ser facilmente aliado a outras temáticas. Neste trabalho buscou-se: (a) identificar os vertebrados representados em mascotes de futebol no Nordeste brasileiro; (b) investigar a percepção de futuros professores de Ciências sobre as temáticas Educação Ambiental, fauna nativa e futebol e; (c) propor oficinas aliadas à essas temáticas para o ensino de Ciências. A pesquisa teve início com o levantamento de informações sobre mascotes de animais nos times de futebol de maior expressão no Nordeste do Brasil. Posteriormente, verificou-se que os futuros professores utilizariam as oficinas propostas ao ministrarem aulas de Ciências. Desse modo, este estudo mostrou como aproximar temas do cotidiano como o futebol à fauna nativa e Educação Ambiental em sala de aula. Espera-se que professores tenham acesso às oficinas propostas a fim de contextualizar conceitos biológicos sobre vertebrados nativos a partir de mascotes em times brasileiros de futebol.
\end{abstract}

Palavras-chave: Educação Ambiental; Mascotes de Futebol; Cultura Local.

Abstract: The football theme can be worked on in several curricular subjects, as well as it can be easily combined with other themes. This work sought to: identify vertebrates represented in soccer mascots in Northeastern Brazil, investigate the perception of future Science teachers on the themes of Environmental Education, native fauna and soccer, in addition to proposing workshops allied to these themes for the teaching of Science. The research began with a survey of information about animal mascots in the most important soccer teams in Northeast Brazil. Later, it was found that future teachers would use the proposed workshops when teaching Science classes. Thus, this study showed how to bring everyday themes such as football closer to native fauna and Environmental Education in the classroom. It is expected that teachers have access to the proposed workshops in order to contextualize biological concepts about native vertebrates from mascots in Brazilian soccer teams.

Keywords: Environmental Education; Soccer Mascots; Local Culture.

\footnotetext{
1 Universidade Federal do Piauí - UFPI. Email: f.alvesdehelenaira@hotmail.com.

2 Universidade Federal do Piauí - UFPI. Email: arlandesales@outlook.com.

Link Lattes: http://lattes.cnpq.br/8223619421196688

3 Universidade Federal do Piauí - UFPI. Email: leticiasousa003@gmail.com.

Link Lattes: http://lattes.cnpq.br/1052716537202472

${ }^{4}$ Universidade Federal do Piauí - UFPI. Email: pnapolis@uol.com.br.

Link Lattes: http://lattes.cnpq.br/4594780742425829
} 


\section{Introdução}

O Brasil é um dos países que apresentam visibilidade nos esportes, com destaque para o futebol que é o mais praticado no país (DAMATTA, 1982; SILVA-JÚNIOR, 2015). Essa visibilidade foi reforçada em $2014 \mathrm{com}$ a sede da Copa do Mundo e as Olimpíadas de 2016. Além disso, ressalta-se a importância do futebol como forte elemento de identidade cultural dos brasileiros, principalmente em anos de conquistas de títulos que o espírito de patriotismo fica mais evidente. Essa amplitude e popularidade do futebol despertaram interesses da mídia, favorecendo para divulgação de marcas, produtos e serviços (GASTALDO, 2009; BRITTOS; SANTOS, 2013).

As questões de marketing também podem ser encontradas na diversidade de espécies representadas como mascotes animais em esportes como o futebol. No Brasil existem mais de 742 clubes profissionais (BRASIL, 2019) e cada um está representado por personagens ou mascotes fortemente antropizados. Contudo, há uma baixa representatividade da fauna nativa e os times enfatizam, sobretudo, espécies de aves e mamíferos (STRAUBE, 2010; BRANDÃO et al., 2016) em detrimento dos répteis, anfíbios e peixes (BRANDÃO et al., 2015; BRANDÃO; BARROS, 2017). Uma das justificativas é que esses grupos se assemelham a humanos e em marketing as características físicas humanas são um método habitualmente usado para aumentar as vendas e/ou a aceitação dos produtos (WANG; ANIRBAN, 2016).

No contexto educacional, questões atuais como às relacionadas ao futebol podem estimular debates, novos conhecimentos e aprendizado dos estudantes, além de propiciar aulas críticas. De acordo com Loureiro e Layrargues (2013), esta criticidade favorece para a formação de valores, atitudes e habilidades voltadas para a identificação e solução dos problemas. Tal perspectiva sugere possibilidades para Educação Ambiental (EA) dentro e fora do ambiente escolar, principalmente ao levar-se em consideração que a Educação Ambiental, assim como o futebol, apresenta-se do global ao local. No entanto, a EA demanda construção da consciência ambiental com a aplicação de práticas educativas contextualizadas em cada região (SATO, 2002; SAUVÉ, 2005).

Diante da biodiversidade brasileira, com mais de 9 mil espécies de vertebrados catalogadas (BRASIL, 2014) e a magnitude futebolística, diferentes espécies nativas poderiam ser conhecidas pela população por meio de mascotes animais em times de futebol. O tema futebol pode ser trabalhado em várias disciplinas curriculares, assim como pode ser facilmente aliado à Educação Ambiental. Desta forma, este trabalho teve como objetivos: (a) identificar vertebrados representados em mascotes de futebol no Nordeste brasileiro; (b) investigar a percepção de futuros professores de Ciências sobre fauna nativa, futebol e Educação Ambiental; e (c) propor oficinas aliadas à Educação Ambiental, futebol e fauna nativa para sala de aula, particularmente no ensino de Ciências. 


\section{Procedimentos Metodológicos}

A presente pesquisa é de caráter qualitativo, com desenvolvimento em três etapas: 1- levantamento bibliográfico; 2- coleta de dados empíricos e; 3propostas de Educação Ambiental. De acordo com Lüdke e André (2013), a pesquisa com aporte teórico metodológico qualitativo possui característica na fonte direta de dados, que são coletados de forma predominantemente descritiva, ao focar a realidade de forma complexa e contextualizada. Em virtude da proposta de Educação Ambiental aqui sugerida, essa pesquisa também está pautada nos pressupostos da Pesquisa-Ação, com a finalidade de estimular a busca de soluções e obter respostas a partir de uma ação transformadora dos participantes (THIOLLENT, 2011).

Com o intuito de identificar os animais nativos utilizados como mascotes nos times de futebol para a região Nordeste, foi realizado um levantamento de dados no site de escudos dos times de futebol no Brasil (disponível em <https://www.escudosfc.com.br/bra.htm>.). Este levantamento ocorreu durante o mês de março de 2021. Na ocasião, foram selecionados somente times do Nordeste que tinham como mascotes animais vertebrados, pois estes são comumente mais representados nos times de futebol.

Após o levantamento foi aplicado um questionário semiestruturado à 24 estudantes do curso de Licenciatura em Ciências da Natureza, da Universidade Federal do Piauí (UFPI). Os estudantes possuíam idade variando de 18 a 30 anos. A aplicação do questionário ocorreu em junho de 2021, de forma remota por meio de formulários do Google Forms. Nesta Etapa, foi verificada a percepção dos entrevistados sobre a fauna nativa, futebol e Educação Ambiental. Os participantes foram questionados sobre essas temáticas porque estes serão futuros professores de Ciências, os quais devem apresentar conhecimentos básicos sobre zoologia e sua relação com outras temáticas como EA, por exemplo.

A partir dos exemplos de animais encontrados nas etapas 1 e 2 foi elaborada uma proposta para inserção da Educação Ambiental no ensino de Ciências, a partir das temáticas fauna nativa e futebol. A proposta está direcionada a estudantes do $7^{\circ}$ ano do ensino fundamental, entretanto pode ser adaptada para estudantes da $2^{\underline{a}}$ série do ensino médio. A seleção desse público pode ser justificada porque são nas aulas de Ciências ou Biologia que os estudantes vivenciam conteúdos relacionados ao Meio Ambiente, Evolução e Seres vivos (BRASIL, 2017).

\section{Resultados e discussão}

Durante o levantamento foi verificado que 52 times possuíam vertebrados como mascotes no Nordeste do Brasil. O grupo dos mamíferos obteve o maior número de mascotes $(n=12 ; 23,08 \%)$, seguido das aves $(n=$ 10; 18,8\%) (Figura 1). Dentre mascotes encontrados, 27 eram da fauna regional. No caso dos mamíferos, diferentes pesquisas sugerem que tais 
mascotes apresentam maior aceitabilidade ou julgamentos estéticos positivos quando comparado ao grupo dos peixes, por exemplo (DYDYNSKI; MAEKIVI, 2017). Além disso, a presença de mascotes para esse grupo pode ser decorrente de marketing, que é usado para aumentar as vendas e a aceitação de produtos em virtude à proximidade das características físicas entre estes vertebrados e os humanos (ALVES, 2012).

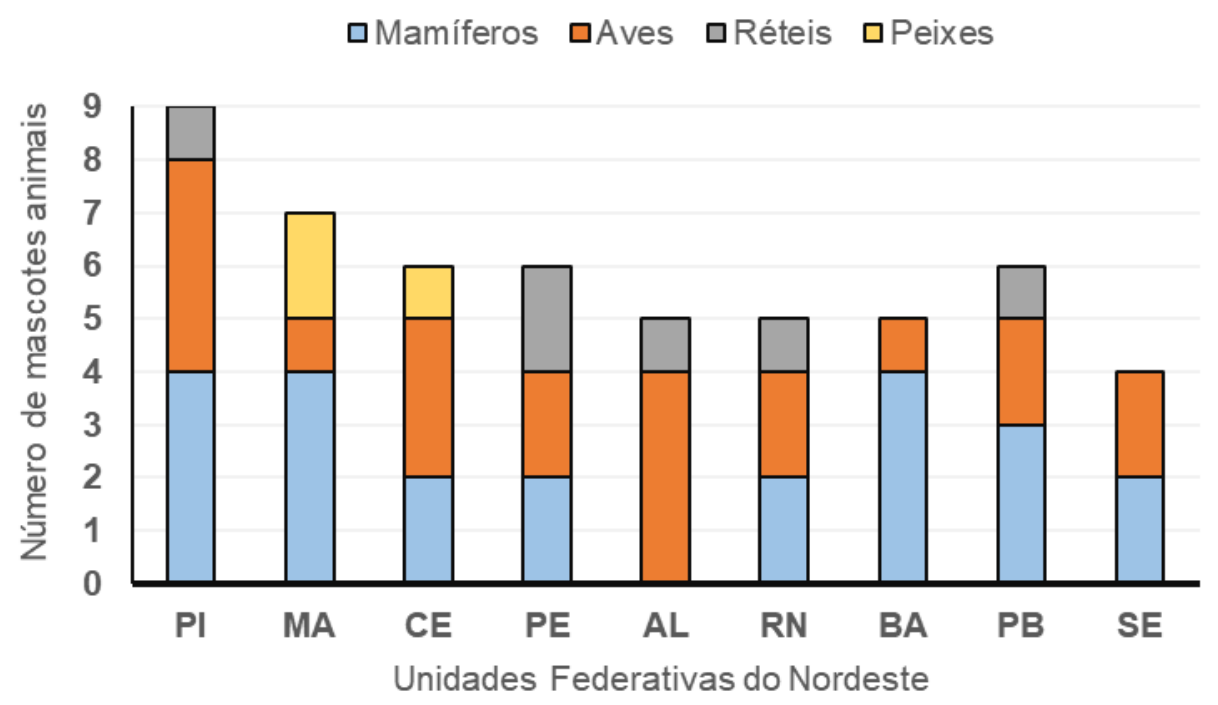

Figura 1: Quantidade de times selecionados por estados da região Nordeste e grupos animais representados. Fonte: Os autores (2021).

Em relação às aves, elementos avifaunísticos estão presentes em diferentes culturas e etnias, desde símbolos mágico-religiosos, alimentação, estimação e até mesmo nos mecanismos de comunicação como pinturas de povos antigos (SODHI et al., 2011). A megadiversidade de aves em sinergia com atributos como canto e diversidade de cores são atrativos (PRESTI et al., 2017; WHITE; EBERSTEIN; SCOTT, 2018) que podem condicionar a escolha desses animais como mascotes em times brasileiros. Em contrapartida, répteis e anfíbios são menos favorecidos pelo marketing futebolístico, uma vez que os representantes desses grupos tendem a despertar atitudes negativas, incluindo o medo, nojo e repulsa a muitos humanos (DIAS; LIMA; FIGUEIREDO-DEANDRADE, 2018), como os sapos e cobras, por exemplo. Adicionalmente, eles podem apresentam menor aceitabilidade ou julgamentos estéticos negativos, 0 que não é recomendável para marketing (DYDYNSKI; MAEKIVI, 2017).

Similar aos resultados encontrados no levantamento, foi observado que quando os futuros professores de Ciências foram indagados a citarem mascotes de futebol que eles conheciam, não houve nenhum réptil ou anfíbio. Entre os exemplos citados estavam: urubu (Família Cathartidae) $(n=9)$, leão (Phantera leo) $(n=8)$, gavião (Família Accipitridae) $(n=5)$, galo (Gallus gallus domesticus) $(n=5)$, porco (Sus scrofa domesticus) $(n=5)$, raposa (Cerdocyon 
thous) $(\mathrm{n}=3)$ e periquito/papagaio (Psittaculidae) $(\mathrm{n}=2)$. Animais mascotes como baleia (Ordem Cetacea), tatu-bola (Tolypeutes tricinctus), asa-branca (Patagioenas picazuro), azulão (Cyanoloxia brissoni), carcará (Caracara plancus) e tamanduá-bandeira (Myrmecophaga tridactyla) foram citados.

Um fator interessante é a presença marcante dos predadores topo de cadeia alimentar, tanto nos achados do levantamento quanto dos questionários. Por exemplo, no grupo dos mamíferos se destacaram os grandes felinos como leão e no grupo das aves encontrava-se o gavião. No geral, esses vertebrados contam com força, sabedoria, agilidade e eficiência para capturar suas presas (POUGH; HEISER; MCFARLAND, 2003). No caso dos times de futebol, essas características são apropriadas para intimidar o adversário, provavelmente por isso ao menos um dos times de futebol nos diferentes estados do Nordeste possuíam um predador como mascote.

Outro ponto relevante é o fato de que mesmo diante da biodiversidade brasileira, as aves adotadas pelos times ou citadas pelos futuros professores de Ciências como mascotes são principalmente espécies domesticadas, de estimação ou alvos do tráfico ilegal de animais silvestres. Vertebrados domésticos como galo, porco e cavalo (Equus caballus) foram representados como mascotes, inclusive citados pelos entrevistados. Caso similar ocorreu com as aves periquito e azulão, que são comumente usadas como pets ou comercializadas na região Nordeste (BEZERRA; ARAÚJO; ALVES, 2012; SOUTO et al., 2017).

Desse modo, destaca-se a importância de a biodiversidade brasileira ser mais conhecida e divulgada pela mídia, professores e demais indivíduos, pois mascotes de times de futebol que representam espécies animais encontradas na natureza podem apresentar algum grau de ameaça desconhecido pela população. Além disso, o Brasil é um dos países mais biodiversos do mundo e essa diversidade deve ser mais conhecida e explanada em diferentes áreas científicas.

\section{Possibilidades de Educação Ambiental com mascotes animais}

Buscou-se fazer uma aproximação entre Educação Ambiental e futebol por meio de mascotes dos times brasileiros, mas especificamente da região Nordeste do país. O foco foi os grupos de vertebrados terrestres (mamíferos, répteis, anfíbios, aves e peixes). Mediante isso, sugeriu-se uma proposta organizada em três oficinas temáticas com duração de 50 minutos cada, visto que corresponde a uma aula ministrada (Quadro 1). Em virtude da pandemia COVID-19 as oficinas não puderam ser aplicadas aos estudantes, porém estas foram avaliadas conforme a percepção de futuros professores de Ciências. 
Quadro 1: Proposta de Educação Ambiental e futebol para o ensino de Ciências.

\begin{tabular}{|c|c|c|c|}
\hline PROPOSTAS & OBJETIVO & MATERIAL & PRODUTO \\
\hline $\begin{array}{c}\text { Oficina 1: Futebol e } \\
\text { Educação Ambiental }\end{array}$ & $\begin{array}{c}\text { Relacionar as } \\
\text { vivências no futebol à } \\
\text { EA }\end{array}$ & Cartolina & Mapa conceitual \\
\hline $\begin{array}{c}\text { Oficina 2: Mascotes } \\
\text { nativas e exóticas }\end{array}$ & $\begin{array}{c}\text { Familiarizar os } \\
\text { estudantes com a } \\
\text { biodiversidade } \\
\text { brasileira }\end{array}$ & $\begin{array}{c}\text { Papel A4 } \\
\text { Caneta/lápis }\end{array}$ & $\begin{array}{c}\text { Desenhos } \\
\text { Listagem livre }\end{array}$ \\
\hline $\begin{array}{c}\text { Oficina 3: } \\
\text { Pertencimento e } \\
\text { valorização faunística }\end{array}$ & $\begin{array}{c}\text { estudantes o } \\
\text { conhecimento de } \\
\text { espécies locais }\end{array}$ & $\begin{array}{c}\text { Tiras de papel A4 } \\
\text { com perguntas }\end{array}$ & $\begin{array}{c}\text { Jogo de } \\
\text { perguntas e } \\
\text { respostas }\end{array}$ \\
\hline
\end{tabular}

Fonte: Os autores (2021).

Dentre os entrevistados, 19 relataram que utilizariam oficinas em suas aulas enquanto professores de Ciências. De acordo com eles, as oficinas contribuem na aprendizagem, uma vez que possibilitam relacionar teoria e prática. Como exemplos das respostas citadas pelos participantes $(\mathrm{P})$ tem-se:

P1: "As oficinas são instrumentos poderosos para o aperfeiçoamento didático, inovação, troca de experiências e construção de conhecimentos".

P2: Por meio das oficinas é possível aproximar os conteúdos à realidade através de uma prática de ensino.

P3: "As oficinas são uma forma lúdica para envolver o aluno na atividade que vai ser realizada".

P4: "Oficinas podem auxiliar no aprendizado, ampliando o conhecimento para que o aluno utilize no seu dia a dia".

P5: "Com a aplicação de oficinas pode-se explorar de forma mais participativa a forma como os alunos veem determinado tema".

A percepção dos futuros professores de Ciências corrobora com a idealização das oficinas propostas, uma vez que estas poderão favorecer para o aprendizado mais prazeroso e dissociado do ensino meramente memorístico e descontextualizado da realidade dos estudantes. No entanto, como a proposta está embasada nos pressupostos da Educação Ambiental, buscou-se verificar a percepção dos entrevistados sobre a temática. A seguir pode ser observado alguns exemplos das respostas reportadas:

P3: "Educação ambiental pra mim é saber da minha importância como parte do meio ambiente onde estou inserido. Como posso atuar e melhorar a questão ambiental onde convivo no dia a dia".

P6: "Educação Ambiental é a compreensão dos conceitos relacionados com o meio ambiente, sustentabilidade, preservação e conservação, com o objetivo de forma cidadãos conscientes". 
P9: "Educação Ambiental é uma temática que contribui para a sensibilização do cidadão em relação aos cuidados com o meio ambiente e a sustentabilidade".

P13: "É a educação voltada a formação de pessoas que se preocupem com a preservação de recursos ambientais, com a preservação da fauna e da flora, etc".

P19: "É educar, tanto jovens e adultos, a ter sensibilidade da importância do meio ambiente".

Diante da percepção dos entrevistados sobre Educação Ambiental, pode-se verificar que eles apresentam conhecimentos sobre a temática, inclusive reconhecem a sua importância. Esses achados são relevantes, principalmente em se tratando de futuros professores nos quais a busca por uma aproximação entre os princípios da Educação Ambiental e as atitudes do cotidiano dos estudantes são práticas que contribuem diretamente no ensino e na aprendizagem. Para Delizoicov; Angotti e Pernambuco (2011) o aluno deve ser 0 agente principal no processo de ensino e aprendizagem.

Nesta perspectiva, levar para a sala de aula conteúdos do dia a dia como o futebol favorece discussões, problematização e participação ativa dos estudantes. Dentre os futuros professores de Ciências entrevistados, 13 relataram que gostam de futebol e 11 que não gostam. Quando questionados se conheciam os times de futebol da região Nordeste, 16 reportaram que sim e oito não conhecem. Todos sabem o que é mascote no time de futebol, porém um dos entrevistados não sabia que animais são comumente utilizados como mascotes nos times de futebol do Brasil e de outros países.

Com a oficina 1, citada no Quadro 1, o docente tem a possibilidade de associar conceitos de EA com às práticas futebolísticas. Inicialmente, ele deve questionar os estudantes o que é Educação Ambiental? Exemplos desta educação nos jogos de futebol. Como exemplificação o docente pode citar o descarte do lixo consumido durante a partida, o consumo de água pelos jogadores e público, a poluição sonora, a desigualdade social nas arquibancadas, dentre outros. Posteriormente, o decente deverá formar grupos de discussões nos quais cada grupo será responsável por elaborar um mapa conceitual para sumarizar as ideias em comum.

De acordo com os entrevistados, exemplos de Educação Ambiental nos jogos de futebol poderiam ser associados a extinção de espécies, destruição de áreas verdes, poluição e outros, como pode ser observado nos exemplos abaixo:

P7: "Geralmente a Copa do mundo traz um animal em extinção como tema da Copa. A última delas foi o tatu bola (fuleco). Eles fazem isso como forma de crítica e conscientizadora sobre as caças desses animais e sua possível extinção".

P12: "Um exemplo, é time inglês "forest green rovers" que leva a mensagem de preservação ambiental como seu ideal". 
P21: "Na destruição das áreas verdes para construções de estádios, não havendo um melhor aproveitamento daquelas regiões".

P22: "Por meio de manifestações por meio de jogadores e torcida para aderir a qualquer questão ambiental".

P24: "Não jogar lixo no gramado ou arredores dos estádios".

Com tais respostas, é perceptível que os futuros professores apresentam discussões que podem proporcionar novos conhecimentos e pensamentos críticos aos estudantes. "Essas aprendizagens, entre outras, possibilitam que os alunos compreendam, expliquem e intervenham no mundo em que vivem" (BRASIL, 2017, p. 323). Ao utilizar estratégias de ensino que vão além de aulas expositivas, o educador desperta nos estudantes o interesse pelo aprendizado, contribuindo para que eles se sintam motivados a exteriorizar seus conhecimentos - neste caso acerca da EA e futebol.

$\mathrm{Na}$ oficina 2 o professor tem a oportunidade de familiarizar os estudantes com espécies da fauna brasileira. Inicialmente, os estudantes devem ser questionados sobre o que é espécie nativa? O que é uma espécie exótica? Posteriormente, o docente solicitará aos estudantes que nomeiem espécies conhecidas a partir de experiências diretas (natureza, parques, escola, residência) e espécies da fauna exótica amplamente divulgada nos meios de comunicação. $O$ docente pode estabelecer o tempo de 5 a 10 minutos, dependendo dos grupos de vertebrados contemplados. Neste caso, o professor deve se atentar a todos os grupos, dado que comumente aves e mamíferos são mais conhecidos do que a herpetofauna e isso inviabiliza o conhecimento e conservação de certas espécies, não menos importantes.

Com o intuito de identificar quais animais seriam citados pelos entrevistados, eles foram convidados a exemplificarem os 10 animais que viessem a sua mente. Verificou-se que a maior parte dos nomes de animais citados pertenciam ao grupo de mamíferos ou aves, como pode ser verificado na Figura 2. Uma tendência similar àquela encontrada durante o levantamento de mascotes em times de futebol, sugerindo que esses vertebrados são amplamente divulgados pelos meios de comunicação, considerados espécies emblemáticas e utilizados como símbolos para despertar o interesse público pelo animal e seu habitat (ALBERT; LUCKE; COURCHAMP, 2018). 


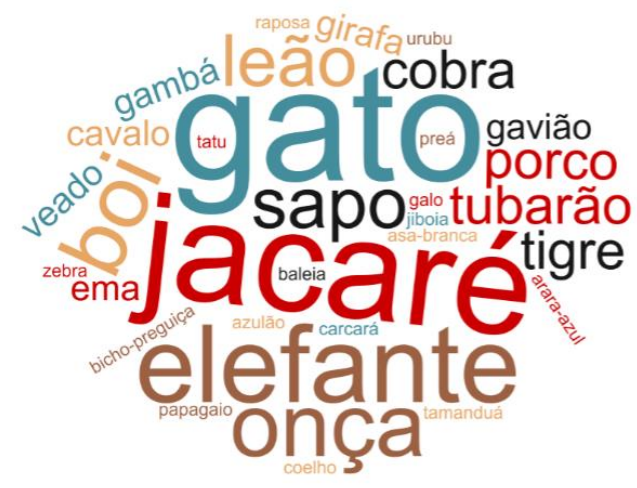

Figura 2: Nuvem de palavras dos animais citados por futuros professores de Ciências.

Fonte: Os autores (2021).

Durante a oficina 2 os estudantes podem fazer desenhos a fim de representarem espécies brasileiras. Isso provocará os alunos a se atentarem mais nos animais e, provavelmente, contribuirá para um maior reconhecimento da fauna nativa, assim como dos animais representados em mascotes de futebol. Essa oficina também estimula a mente dos participantes para que se lembrem dos animais e de suas características com base nos seus conhecimentos, sem necessariamente ter ajuda do professor ou dos livros didáticos utilizados em sala de aula. Eles poderão associar mascotes como galo-de-campina, azulão, raposa e jacaré, dentre outros em seus desenhos.

A oficina 3 desperta nos alunos o cuidado e, consequentemente um sentimento de pertencimento. Isso facilita para que o docente trabalhe questões de conservação do meio ambiente e sua biodiversidade associada. Para isso, o docente deve elaborar questões sobre a fauna local como, por exemplo: Qual a ave símbolo do estado que o estudante reside? Qual é o mamífero considerado o maior dos roedores da região? Qual é o mamífero da região que leva a vida em "câmera lenta" e possui grandes garras que são utilizadas para subir e permanecer na copa de árvores como a embaúba? O professor pode optar por fazer jogos ilustrativos, similar a Barros; Ortolano e Fujihara (2018), tornando a aula ainda mais participativa.

Quando os futuros professores de Ciências foram questionados sobre a ave símbolo do estado do Piauí, sete relataram o surucuá-de-barrigavermelha (Trogon curucui), sete responderam outros animais e 10 não souberam responder. Com relação ao maior roedor da região, 19 reportaram a capivara (Hydrochoerus hydrochaeris), um deles citou a anta (Tapirus terrestris) e quatro não souberam responder. Diante desses dados, destaca-se a importância de professores de Ciências estarem mais familiarizados com a fauna local, pois assim poderão apresentar espécies encontradas na localidade dos estudantes (por exemplo, na escola, arredores de casa e parques). 
As três oficinas aqui apresentadas buscam melhor aliar o futebol aos conteúdos em sala de aula. Elas contribuem para o pensamento crítico que pode ser desenvolvido a partir de observações nas cores retratadas em mascotes, nos formatos do animal, nas características e afins. Se tais informações são condizentes com 0 animal na natureza ou está apenas representando as cores do clube, personificações humanas etc. Assim, é por meio de atividades diferenciadas voltadas ao meio ambiente como um todo que os estudantes se reconhecem como cidadãos ativos e motivados a transformarem a realidade que os cercam (CARVALHO, 2012; REIGOTA, 2012).

\section{Considerações finais}

Este estudo mostrou como os professores de Ciências podem aproximar temas do cotidiano como o futebol à fauna nativa e Educação Ambiental em sala de aula. Espera-se que professores tenham acesso às oficinas propostas e que possam contextualizar os conceitos biológicos acerca dos vertebrados a partir de mascotes em times do Nordeste do Brasil. Destacase, entretanto, que as propostas podem ser adaptadas conforme os animais símbolos nos times de futebol distribuídos por todas as regiões do país.

Com relação à presença de mascotes nos times de futebol do Nordeste, sugere-se que: (a) os animais nativos sejam mais retratados que os exóticos; (b) a diversidade biológica da fauna brasileira seja mais bem representada; (c) que os times representem mais espécies de répteis, anfíbios e peixes; (d) que os times retratem as características do animal de acordo com o exemplar na natureza e não como personificação para fins de marketing.

\section{Referências}

ALBERT, C.; LUQUE, G. M.; COURCHAMP, F. The twenty most charismatic species. PloS one, v. 13, n. 7, 2018.

ALVES, R. R. N. Relationships between fauna and people and the role of ethnozoology in animal conservation. Ethnobiology and conservation, v. 1, 2012.

BARROS, J. D.; ORTOLANO, S. M. C. M.; FUJIHARA, R. T. Zoo cards-o super trunfo animal: um jogo didático como ferramenta para o ensino no zoológico. Revista Brasileira de Educação Ambiental, v. 13, n. 1, p. 145-155, 2018.

BEZERRA, D. M. M.; ARAUJO, H. F. P.; ALVES, R. R. N. Captura de aves silvestres no semiárido brasileiro: técnicas cinegéticas e implicações para conservação. Tropical Conservation Science, v. 5, n. 1, p. 50-66, 2012.

BRANDÃO, L. E. D. et al. Anfíbios e répteis representados nas mascotes dos times brasileiros de futebol. Anais do III Encontro Regional de Ensino de Biologia, p. 1-11, 2015. 
BRANDÃO, L. E. D. et al. Os mamíferos representados como mascotes dos times brasileiros de futebol. Trilhas Pedagógicas, v. 6, n. 6, p. 74-91, 2016.

BRANDÃO, L. E. D.; BARROS, M. D. M. Os peixes representados como mascotes dos times brasileiros de futebol. Ensino \& Pesquisa, 2017.

BRASIL. Ministério da Educação. Secretaria da Educação Básica. Base Nacional Comum Curricular. Brasília, DF, 2018. Disponível em: $<$ http://basenacionalcomum.mec.gov.br/wpcontent/uploads/2018/02/bncc20dez-site.pdf>. Acesso em 27 de abril de 2020.

BRASIL. Confederação Brasileira de Futebol - CBF. Disponível em: $<$ https://www.cbf.com.br>. Acesso em: 28 jan. 2020

BRITTOS, V. C.; SANTOS, A. D. G. Processos midiáticos do esporte: do futebol na mídia para um futebol midiatizado. Comunicação Mídia e Consumo, v. 9, n. 26, p. 173-190, 2013.

CARVALHO, I. C. M. Educação ambiental e a formação do sujeito ecológico. 6 ed. São Paulo: Cortez, 2012.

DAMATTA, R. Esporte na sociedade: um ensaio sobre o futebol brasileiro. Universo do futebol: esporte e sociedade brasileira. Rio de Janeiro: Pinakotheke, p. 19-42, 1982.

DELIZOICOV, D.; ANGOTTI, J. A.; PERNAMBUCO, M. M. Ensino de ciências fundamentos e métodos. 4. ed. São Paulo: Cortez, 2011.

DIAS, M. A. S.; LIMA, N. B.; FIGUEIREDO-DE-ANDRADE, C. A. Análise do Conhecimento etno-herpetológico dos estudantes no Município de Salinas, Minas Gerais, Brasil. Acta Biomedica Brasiliensia, v. 9, n. 1, p. 36-47, 2018.

DYDYNSKI, J.; MÄEKIVI, N. Multisensory perception of cuteness in mascots and zoo animals. International Journal of Marketing Semiotics, v. 6, n. 1, p. 2-25, 2018.

GASTALDO, E. "O país do futebol" mediatizado: mídia e Copa do Mundo no Brasil. Sociologias, n. 22, p. 353-369, 2009.

LOUREIRO, C. F. B.; LAYRARGUES, P. P. Ecologia política, justiça e educação ambiental crítica: perspectivas de aliança contra-hegemônica. Trabalho, educação e saúde, v. 11, n. 1, p. 53-71, 2013.

LUDKE, M.; ANDRÉ, M. E. D. A. Pesquisa em educação: abordagens qualitativas. São Paulo: Editora Pedagógica e Universitária, 2013.

POUGH, F. Harvey; HEISER, John B.; MCFARLAND, William N. A vida dos vertebrados. São Paulo: Atheneu, 2003.

PRESTI, F. T. et al. Conhecendo a arara-azul-grande: confecção e aplicação de um jogo didático como parte das ações de Educação Ambiental visando a conservação da espécie. Revista Brasileira de Educação Ambiental, v. 12, n. 2, p. 259-273, 2017. 
REIGOTA, M. Meio ambiente e representação social. 8. ed. São Paulo: Cortez, 2012.

SATO, M. Educação Ambiental. São Carlos: RiMa, 2002.

SAUVÉ, L. Educação Ambiental: possibilidades e limitações. Educação e Pesquisa, v. 31, n. 2, p. 317-322, 2005.

SILVA-JÚNIOR, I. Como o futebol se tornou o esporte mais praticado no Brasil. Anais do EVINCI-Uni Brasil, v. 1, n. 3, p. 101-101, 2015.

SODHI, N. S. et al. Conservation of Tropical Birds. 1. ed. West Sussex, UK: Wiley-- Blackwell, 324 p.1-300, 2011.

SOUTO, W. M. S. et al. Singing for cages: The use and trade of Passeriformes as wild pets in an economic center of the Amazon-NE Brazil route. Tropical Conservation Science, v. 10, p. 1-19, 2017.

STRAUBE, F. C. As aves nos símbolos do futebol brasileiro: Escudos. Atualidades Ornitológicas On-line, n. 158, 2010.

THIOLLENT, M. Metodologia da pesquisa-ação. São Paulo: Cortez, 2011.

WANG, T.; ANIRBAN, M. How consumers respond to cute products. The psychology of design: Creating consumer appeal, p. 149-167, 2015.

WHITE, R. L.; EBERSTEIN, K.; SCOTT, D. M. Birds in the playground: Evaluating the effectiveness of an urban environmental education project in enhancing school children's awareness, knowledge and attitudes towards local wildlife. PloS one, v. 13, n. 3, p. e0193993, 2018. 